Bangladesh J. Sci. Res. 29(1): 73-83, 2016 (June)

\title{
SOCIO-ECONOMIC AND HEALTH STATUS OF SLUM DWELLERS OF THE KALYANPUR SLUM IN DHAKA CITY
}

\author{
Mahmuda Binte Latif*, Anjuman Irin and Jannatul Ferdaus \\ Department of Environmental Sciences and Resources Management, \\ Mawlana Bhashani Science and Technology University, \\ Santosh, Tangail-1902, Bangladesh
}

\begin{abstract}
This research was carried out to examine the socio-economic and health condition of slum dwellers of Kalyanpur slum area. The study was both qualitative and quantitative type. In quantitative approach, primary data were used and collected from randomly selected (68 respondents) slum dwellers in the Kalyanpur slum area. The secondary data were collected from journal papers, articles, books, official documents, thesis papers, daily newspapers etc. By analyzing the survey, it is seen that slum dwellers were deprived of basic needs. The study helps to identify the slum problems such as food and housing problems, poor sanitation condition, poor quality or no sewerage and drainage, inadequate educational facilities, lack of utility services like gas facility, electricity connection, piped water supply etc. From this study it is observed that every family live in a slum in unhygienic environment in poor condition. The slum dwellers work as garments workers $(24.2 \%)$, household workers (13.7\%), rickshaw pullers $(19.2 \%)$, street hawkers, day labourers, masons etc. The range of household income of slum dwellers was about Tk 6,000 - 10,000 and they spent most of their money on food (61.39\% of income). It was also seen that most of the slum dwellers were affected by various kinds of seasonal and waterborne diseases like fever, asthma, skin diseases, diarrheoa, jaundice etc. The study finds that poor socio-economic status and inadequacy of urban services has had an immediate effect on urban health specially the slum poor in metropolitan cities in the country.
\end{abstract}

Key words: Socio-economic, utility services, health status, slum

\section{Introduction}

Bangladesh has the third largest population in South Asia after India and Pakistan. According to BBS (2011) Bangladesh has an urban population of about 4,19,43,532 or just over $28 \%$ of its total population. Moreover, the urban population has been growing very rapidly since the liberation in 1971 and at present $2.96 \%$ annually (BBS 2011). The country will likely have an urban population approaching 50 million by 2015 . This rapid growth has been occurred by the migration of rural poor particularly to large metropolitan areas. On arrival, these poor migrants routinely turn to slums and squatter settlements for shelter. All major urban centers in Bangladesh have slums and squatter settlements, the concentration being in Dhaka, followed by Chittagong, Khulna and Rajshahi. According to the report of Mahbub et al. (2005) 4,966 slums and squatter clusters and roughly $34,20,521$ slum dwellers (out of a population of 91,36,182) live in the Dhaka Metropolitan area alone.

*Author for correspondence: <mahmudambstu@gmail.com>. 
Abundant anecdotal evidence has suggested that the number of slum settlements and overall slum population in Dhaka city has continued to increase since that time. The health condition in the poor communities in the third world cities is alarming as thousands of children still die every day from preventable diseases related to the inadequate provision of water and sanitation (Bartlett 2003). As elsewhere in the third world, slums and squatters in Bangladesh attracted not much attention from the public health policy makers. The health impact originated from socio-economic status has been extensively studied focusing on mortality and morbidity (Papa et al. 2009). Studies on the effects of environmental factors on slum dweller's health in the context of Bangladesh are scarce. A few studies have been made on urban environmental health situation in the informal settlements (Salahuddin and Islam 1982, Hussain et al. 1999). In both the developed and developing countries, the relation between socio-economic status and health exhibits a common pattern: the lower the socio-economic status the poorer the health (Singh et al. 1996, Papa et al. 2009). In this case most of the slums of Dhaka city are facing various problems and these problems are becoming acute day by day such as intolerable housing conditions, lack of basic services especially drinking water, sanitation and medical treatment, lack of educational facilities, lack of security of tenure, lack of utility services like gas facility, electricity connection, piped water supply, lack of proper solid waste disposal. Most of the slum dwellers are affected by various kinds of both seasonal and waterborne diseases. Kalyanpur slum has been taken as a case study, because this area is situated in the middle of Dhaka city and the living condition of this slum dwellers are very poor. Besides there were no such previous attempt to study with such type of issue of this slum area. This investigation subscribes to the necessity of analyzing the socioeconomic and health condition of slum people which can help to formulate future development plan for the slum. Keeping in mind the above scenario the current study has set out two objectives: to analyze the socio-economic and health condition of the Kalyanpur slum people and to know the opportunities and other difficulties regarding their life and livelihood.

\section{Materials and Methods}

Study area: Kalyanpur slum (pora basti) was selected as study area which is situated at Kalyanpur mahalla under Kalyanpur ward of Mirpur thana in Dhaka district. The Kalyanpur slum (pora basti) is located within latitude of $23^{\circ} 47^{\prime} 05^{\prime} \mathrm{N}$ and longitude of $90^{\circ} 21^{\prime} 49^{\prime} \mathrm{E}$. Mirpur thana is situated in zone no. 4 under Dhaka North City Corporation, Dhaka district. There are eight wards and 57 mahallas in this thana. Among eight wards, Kalyanpur ward is situated in word no.11. This ward is divided into four mahallas. They are Dakshin Paikpara, Madya Paikpara, Paikpara and Kalyanpur mahalla (BBS 2011). The total population of Kalyanpur mahalla is 42,801 , while male population is $55.79 \%$, and female population is $44.21 \%$. The total household and population of Kalyanpur slum (pora basti) is 2,184 and 8,129 (male 4,126, female 3,998 and others 5), respectively (BBS 2015). 


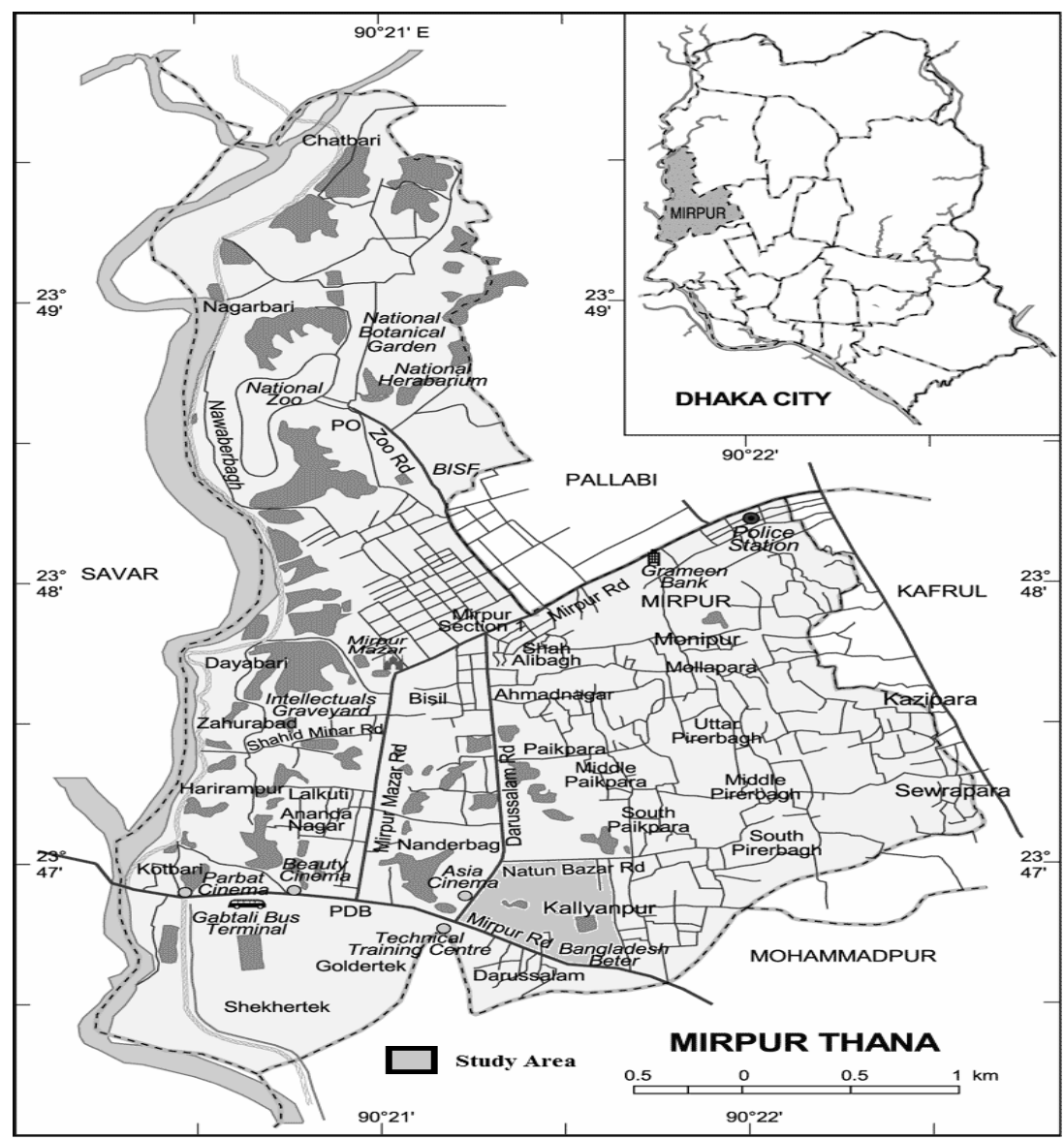

Fig. 1. Map of the study area (Kalyanpur) at Mirpur thana in Dhaka city. Source: (Banglapedia 2008).

Both qualitative and quantitative techniques of data collection were used for this study. The research was carried out on the basis of primary and secondary data. The questionnaire survey was carried out through randomly selected 68 respondents ( 36 male and 32 female) of slum dwellers to collect primary data. Simple random sampling technique was used for selecting sample size. Sample size was determined using the approach as follows: (i) the desired precision/error, (e) is $10 \%$, (ii) the desired confidence level, ( $\mathrm{z}$ ) is $90 \%$, (iii) determine the $\mathrm{z}$ value associated with the confidence level, (iv) the value of $\mathrm{z}$ at $90 \%$ confidence level is 1.645 , (v) In the absence of the target proportion (p) we assumed it to be $50 \%$ i.e. $\mathrm{p}=0.50$ and (vi) total population, $\mathrm{N}=8,129$.

On the basis of the above, sample size $(n)=z^{2}$.p.q.N/ $e^{2}(N-1)+z^{2} . p \cdot q$

[Source: Kothari 1990] $=68$

So, the calculated sample size for the study area was 68 . 
Key informant interview was also conducted with different government and non-government organization (NGOs) authorities in order to know their view about the situation and sustainable solution of the problems. A lot of photographs were collected directly from the field survey. The secondary data were collected from government and non-government official documents and statistics, yearly reports, various books, research papers, journals, maps, daily newspapers etc. Collected data were processed and analyzed by computer based statistical software package SPSS 14.00 for windows seven and Microsoft office Excel 2007 and qualitative descriptive explanation. Finally the analyzed data were integrated and presented as tables, graphs and pie diagrams and put in the paper.

\section{Results and Discussions}

Age and family structure of slum dwellers: According to the field survey data it was shown that among 36 male and 32 female respondents, $34.70 \%$ were of $21-30,31.1 \%$ were of $31-40$, $18.30 \%$ were of $41-50$ age groups and $10.5 \%$ were up to 20 years. Only $5.5 \%$ were within $51+$ age groups. Maximum families were nuclear (55\%) and joint families were 45\%. $70.8 \%$ families had 1 - 3 members and $25.1 \%$ families had 4 - 6 members dependent on their family or not earning. Only $4.1 \%$ family had 7 - 9 members dependent on their family.

Another study was conducted by Hossain et al. (2010) on Khulna and Rajshahi slums naming "Urban environmental health in Bangladesh slum: a comparative study of two metropolitan cities". It showed that in Rajshahi city, 39\% of the respondents fall in the $31-40$ age group and the numbers drop sharply from the age of 40 . More than $45 \%$ are under the age of 30 while $35 \%$ of respondents in Khulna city fall in the 21-30 year-old age group, with a gradual decrease after the age of 30, excluding the age group of 50 years and above.

Status of education facilities: Fig. 2 shows that $50.2 \%$ people were illiterate. Higher educated persons were not at the slum. Some were educated up to primary school $(22.4 \%)$ and some had no formal education.

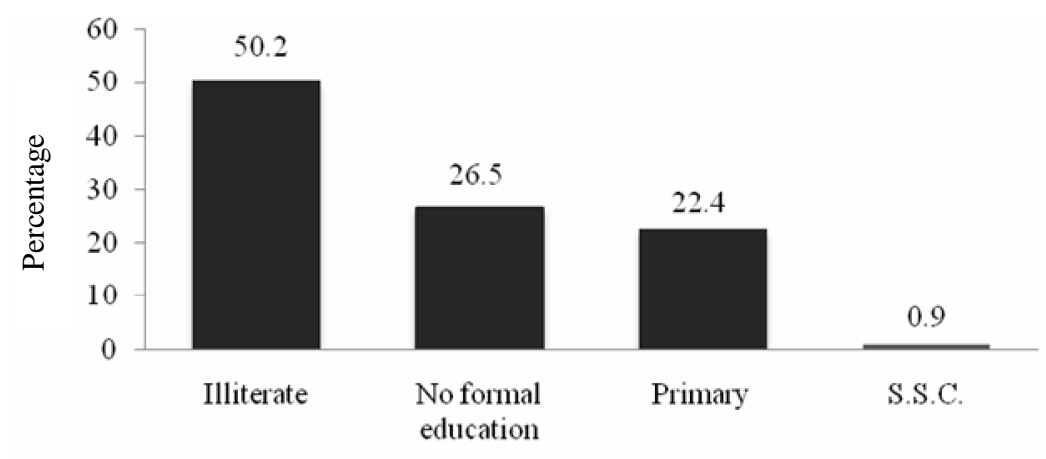

Status of education

Fig. 2. Status of education. 
According to the survey data a few of children (36\%) attended school. Parents were reluctant to send their children to school due to their poverty. Besides this, educational facilities are not available here. Maximum children were going to NGOs' school (51.6\%) and only 5\% children were going to private school and $43.4 \%$ children were going to government primary school.

According to Hossain et al. (2010), the level of education in both cities is very low, ranges from primary to higher secondary levels. In Khulna city overall illiteracy rate is about $60 \%$ whereas in Rajshahi this rate reaches $90 \%$. Only $1.4 \%$ of respondents had a graduate-level education in Rajshahi while in Khulna the figure was nil. There is similarity among the study areas. In Rajshahi city slum and Khulna city slum areas maximum people are illiterate.

District of origin and duration of living in the slum: From the Table 1 it is evident that people in Kalyanpur slum mainly came from Bhola (46.1\%), Noakhali (16.4\%), Patuakhali (13.2\%) and Kishorganj (11.4\%).

Table 1. District of origin of the slum population.

\begin{tabular}{lcc}
\hline District & Frequency & Percentage \\
\hline Bhola & 32 & 47.1 \\
Rajshahi & 2 & 2.94 \\
Kishorganj & 8 & 11.76 \\
Noakhali & 11 & 16.2 \\
Patuakhali & 9 & 13.24 \\
Others & 6 & 8.82 \\
Total & 68 & 100.0 \\
\hline
\end{tabular}

According to the Mahbub et al. (2005) 22.9\% slum people of Dhaka district were from Barisal, 9.1\% from Comilla, 9.2\% from Faridpur, 7.3\% from Mymensingh and 4.6\% from Rangpur. From these studies it is evident that most of the people of slum area came from Barisal district. Most of the people (64.8\%) had been living in this slum for $11-20$ years and 34.2\% for 1-10 years. Only $1.0 \%$ lived here for above 20 years.

Types of settlement and utility service facilities: Generally, the housing structure of slum dwellers was very poor. From study (Fig. 3) it is seen that three categories of housing were found in the study area- pucca (1\%), semi pucca $(20.90 \%)$ and kutcha (78.10\%). All family members of a household (5 - 6 people) lived in a single room in their house (90.4\%) and only $7.8 \%$ lived in two rooms.

According to Hossain et al. (2010) above 72\% of houses in Khulna's slums are kutcha. These are slightly better than jhupri, while about $27 \%$ houses are semi-pucca. Pucca houses constituted less than one per cent. Seventy seven per cent houses, on the other hand, in Rajshahi city are semipucca while approximately $21 \%$ houses are kutcha and over $2 \%$ houses are pucca. From these studies it is found that the semi-pucca and kutcha houses were prominent in slum areas. From the field survey it is found that there was no gas facility for cooking and all of the people (100\%) used 
wood as a fuel for cooking in the study area. According to Mahbub et al. (2005) it is claimed that gas supply was not available in Khulna, Rajshahi and Barisal while about 58\% of the slums of Dhaka did have access to it.

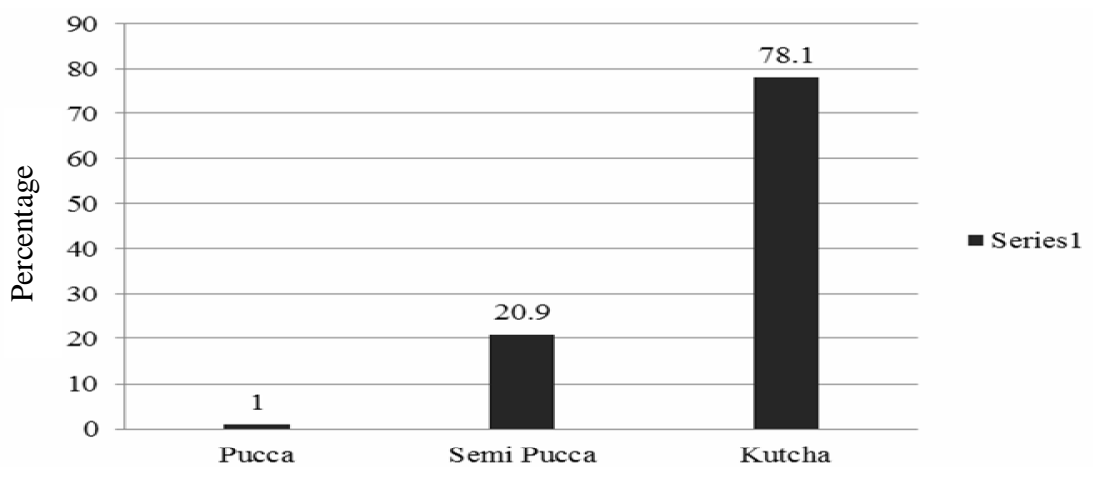

Fig. 3. Types of settlement.

Fig. 4 shows that $69.4 \%$ slum people of Kalyanpur slum used tube-well water, $22.5 \%$ used WASA water and only $9.1 \%$ used well as a source of drinking water and other household works. On the other hand $86.3 \%$ people had access in electricity facilities and $13.7 \%$ had no electricity facility in this area. 53\% slum dwellers used open latrine and $47 \%$ used sanitary latrine. Most of these were in unhealthy condition.

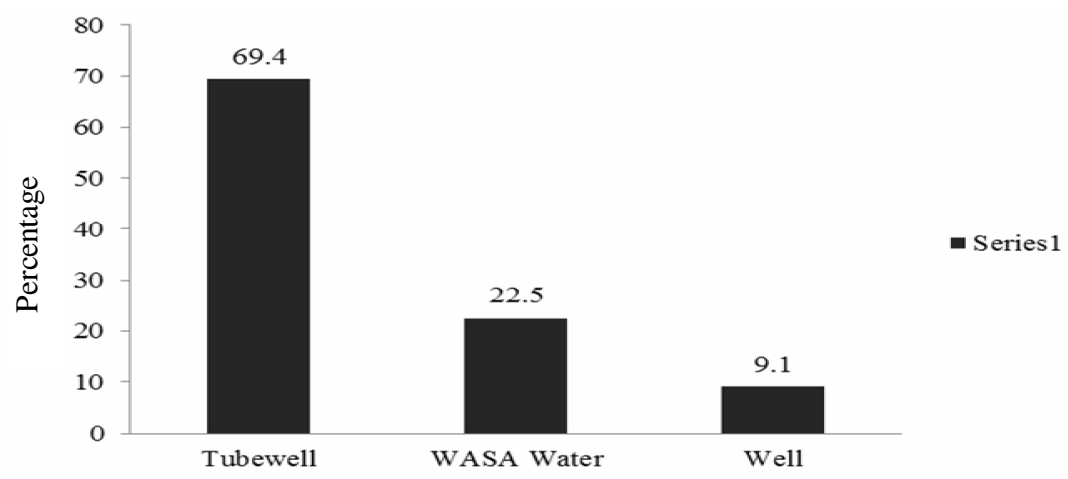

Fig. 4. Sources of drinking water.

According to Hossain et al. (2010) in Rajshahi, 61.21\% of households depend on the community tube-well, which is installed by the city authority. About $34 \%$ rely on individual tube wells; while a small minority of people (3.3\%) has a water connection. Whereas $94 \%$ of slum dwellers in Khulna collect drinking water from the community tube-well and 3\% depend on a neighboring tube-well. The majority of households have access to electricity i.e. $60.7 \%$ in Khulna and $86.1 \%$ in Rajshahi. 
Pattern of occupation of slum dwellers: Fig. 5 shows the nature of work of earning members. According to the survey $24.2 \%$ people were involved in garments factories. 19.2 and $13.7 \%$ people of Kalyanpur slum area were involved in rickshaw pulling and household works, respectively while $18.6 \%$ slum people of Dhaka city worked as day labours, 3.7\% hawkers, $22.4 \%$ factory or garment workers, 5\% domestic or household workers and $24 \%$ transport workers (Mahbub et al. 2005).

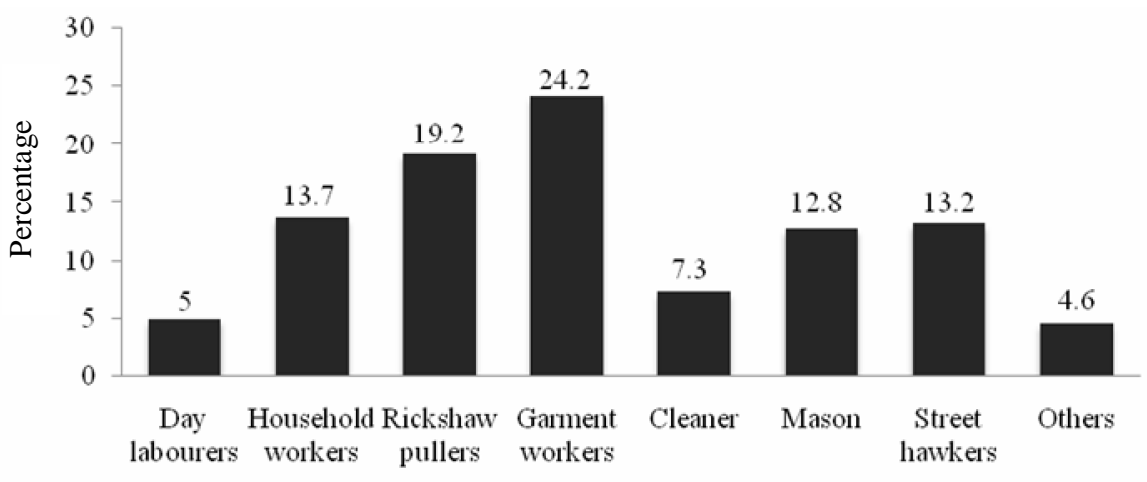

Fig. 5. Nature of work.

Monthly income and expenditure of the household: From the survey (Fig. 6) it is shown that monthly income of $19.17 \%$ households was between Tk 1,000 - 5,000 and 58.9\% was between Tk 6,000 - 10,000 of the study area while 14.6 and 9.13\% household income was Tk 11,000 15,000 and Tk 16,000 - 20,000, respectively in Dhaka city slum (Mahbub et al. 2005).

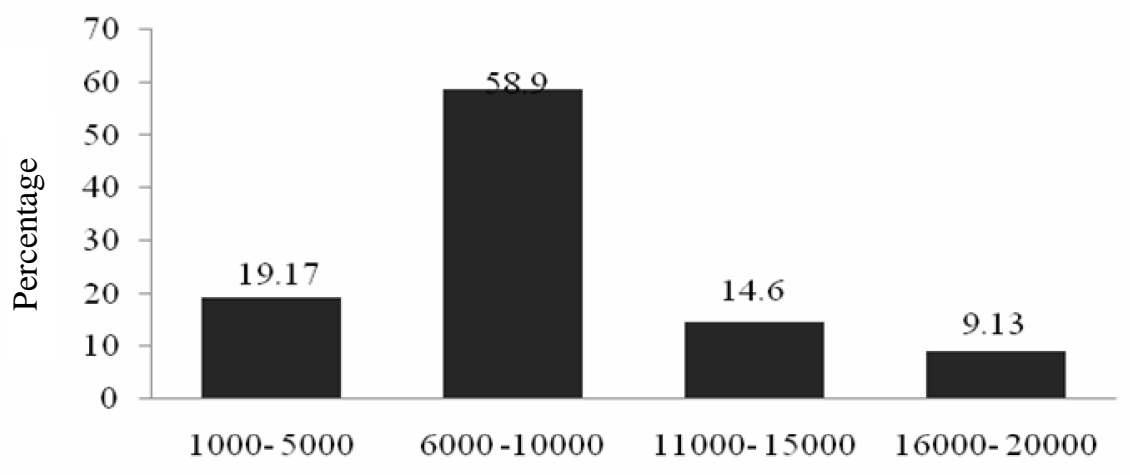

Fig. 6. Monthly income of the households.

Survey data (Fig. 7) revealed that a major share of slum dwellers income was spent on food (61.39\%), health (7.97\%), education (6.99\%) and clothing (4.18\%). 
Most of the people were able to improve their economic condition. $50.2 \%$ respondents answered that their economic condition was better than past 10 years. A few people said that their economic condition was getting poorer than past years. But a significant number $(35.2 \%)$ of people said that their economic condition remained unchanged.

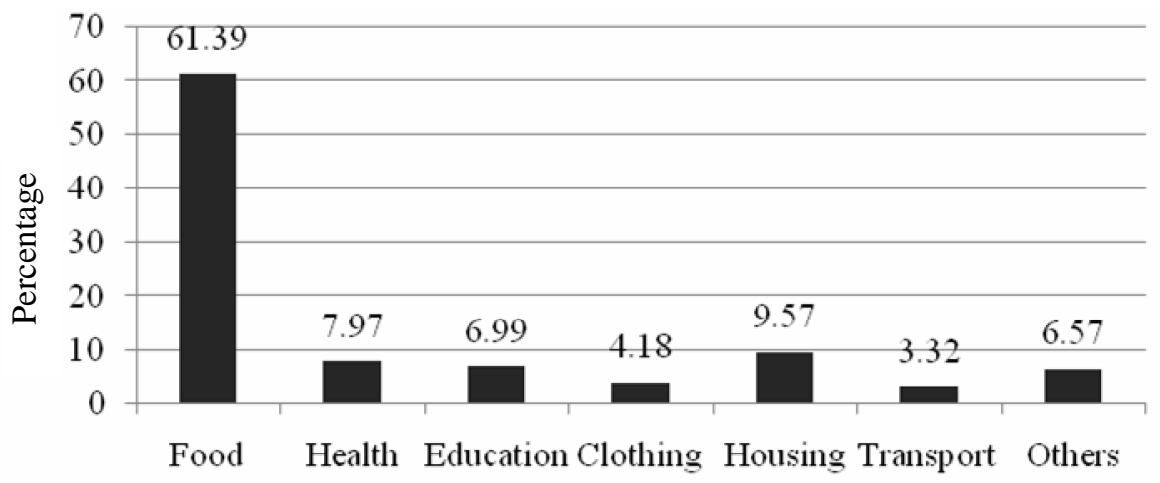

Fig. 7. Expenditure per month.

According to Hossain et al. (2010) it was evident that in Khulna city, household income and expenditure was Tk 3,898 and Tk 3,797 and in Rajshahi it was Tk 3,881 and Tk 3,801. Family savings were very minimal, as most of their income goes on food and non-food items.

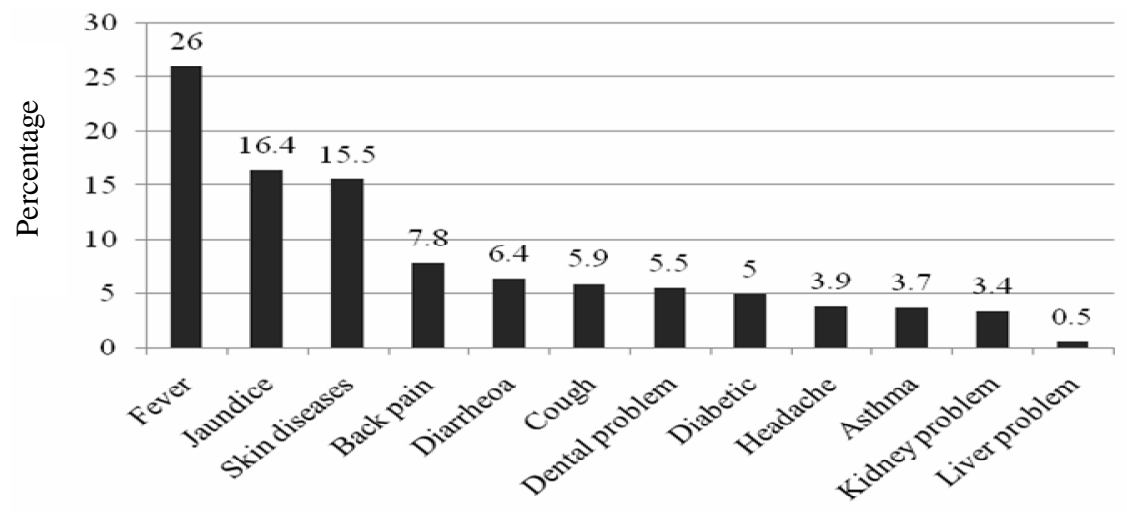

Fig. 8. Diseases that slum people suffering from.

Health condition of slum dwellers: From (Fig. 8) it is seen that most of the people of study area $(26 \%)$ were suffering from fever. 16.4, 15.5 and $6.4 \%$ were suffering from jaundice, skin diseases and diarrheoa, respectively while in Khulna slums, more than $20 \%$ of the respondents had fever followed by gastric problems (16\%), diarrheoa (8\%), high blood pressure (6\%) and headache $(6 \%)$. Other diseases, which were not so prevalent include asthma, heart problems, typhoid, skin 
diseases and so on. In Rajshahi slums, $32 \%$ were reported getting sick, $20 \%$ were suffering from high blood pressure, $27 \%$ fever, $7 \%$ headache, $7 \%$ gastric problems, $6 \%$ skin disease and $6 \%$ heart problems (Hossain et al. 2010).

From the Table 2 it is found that about $33.8 \%$ people said that damp environment was the main reason of affecting diseases.

Table 2. Reasons of causing diseases.

\begin{tabular}{lcc}
\hline Reasons of diseases & Frequency & Percentage \\
\hline Damp environment & 23 & 33.82 \\
Water logging & 13 & 19.12 \\
Water pollution & 19 & 27.94 \\
Open drain & 4 & 5.88 \\
Others & 9 & 13.24 \\
Total & 68 & 100.0 \\
\hline
\end{tabular}

$19.12 \%$ people said that water logging is another important reason of diseases. Moreover, the main reason for jaundice is unhygienic food, unsafe drinking water and open drains.

From the Fig. 9 it is seen that most of the respondents of this slum were dependent on doctors (52\%) for their treatment and go to government hospital (Showrawardi Govt. hospital) but medical service was not available to meet their needs. Most of the respondents said that poverty was the main reason of getting improper treatment. Doctors did not treat them well because they could not pay money. Long time waiting, high ticket price, no free medicine provided by Govt. hospital were other constraints for not getting proper treatment from Govt. hospital. Besides them $46 \%$ people were dependent on Kobiraz because of low cost and their belief.

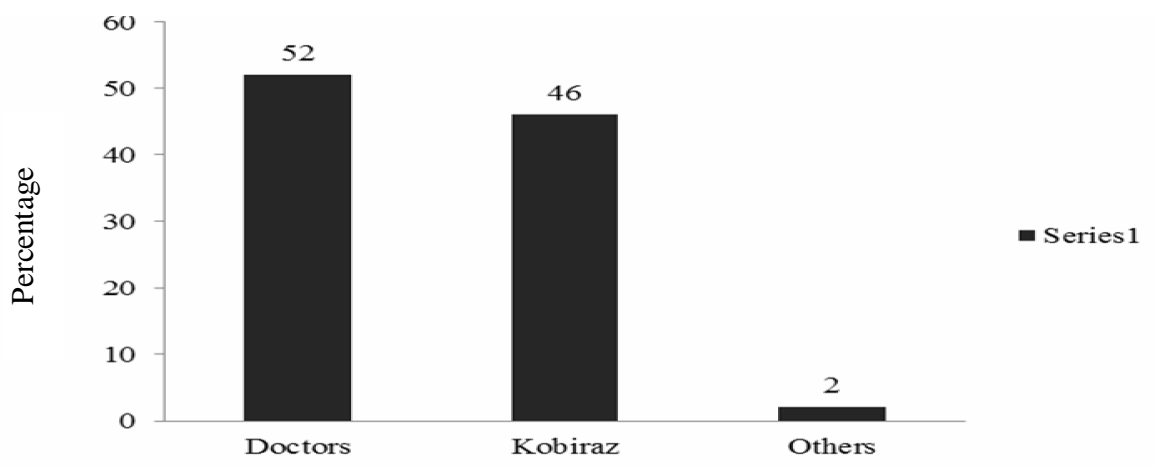

Fig. 9. Pattern of treatment.

NGOs activities were mainly found in poor areas. The study shows that most of the people in the Kalyanpur slum area got better NGOs facility, $42.5 \%$ got moderate facility and very few $(9.6 \%)$ got bad facility. 


\section{Conclusions and Recommendations}

Slum life means a sub-human life being that deprived from fundamental constitutional rights. From the observations, opinion of the respondents, NGO workers, Govt. workers, local and government representatives and previous data, it is clear that the slum dwellers are not facilitated of important fundamental rights like housing and health facilities, job opportunities, sanitation facilities, education etc. The socio-economic and infrastructural condition were not well in Kalyanpur slum.

Results of the field surveys conducted in the Kalyanpur slum and other studies of Mahbub et al. (2005) and Hossain et al. (2010) show that the communities are almost homogenous not only by socio-economic, housing, utility services and political status but also by health condition and some dissimilarity were also visible across housing quality, education and monthly income. Some socio-economic characteristics such as low literacy, poor housing, and lower educational status of the residents in slum dwellers might have had an influence on their health condition.

However, low level of income, inadequate sanitation services, substandard housing and the crammed environment in the slums studied might have impacted on the environment that led to higher morbidity among the slum dwellers.

After identifying problems and extensive evaluation for the sake of welfare of this slum area the following recommendations could be implemented:

a. Government should take initial steps to improve the living condition of slum dwellers, utility service facilities, education facilities, treatment facilities etc.

b. The local administration should take steps to improve solid waste management system and develop sewerage and drainage system of this area.

c. Comprehensive national policies and plans should be developed to promote the benefits and possibilities of extending basic services.

d. For an effective and successful programme there should be intra and inter relationship of the government, NGOs and private organizations that are working for the slum dwellers.

\section{References}

Banglapedia. 2008. National Encyclopedia of Bangladesh, Asiatic Society of Bangladesh, Dhaka, Bangladesh.

Bartlett, S. 2003. Water, Sanitation and Urban Children: The need to go beyond improved provision. Environment and Urbanization 15(2): 57-70.

BBS. 2011. Population and Housing Census: Bangladesh Bureau of Statistics, Statistics Division, Ministry of Planning, Government of the People's Republic of Bangladesh, Dhaka.

BBS. 2015. Preliminary Report on Census of Slum Areas and Floating Population. Bangladesh Bureau of Statistics.

Hossain, M.A., M. Moniruzzaman and M.A. Islam. 2010. Urban Environmental Health in Bangladesh Slum: A Comparative Study of Two Metropolitan Cities. J. Sci. Foundation 8(1\&2): 67-76.

Hussain, A., S.M.K. Ali and G. Kvale. 1999. Determinants of mortality among children in the urban slums of Dhaka city, Bangladesh. Tropical Medicine \& International Health 4(11): 758-764. 
Kothari, C. R. 1990. Research Methodology, 2nd Edition, New Age International (P) Limited, India. p. 179.

Mahbub, A.Q.M., G. Angeles, P. Lance, N.I. Nazim. 2005. Centre for Urban Studies: Slum of Urban Bangladesh: Mapping and Census 2005.

Papa, E., N. Kontodimopoulos, A. Angelos, A.A. Papadopoulos and D. Niakas 2009. Assessing the socioeconomic and demographic impact on health-related quality of life: Evidence from Greece. International Journal of Public Health 54.

Salahuddin, A. K. M. and M. S. Islam. 1982. Status of Environmental Sanitation of a Slum Area in Dhaka City. Journal of Preventive and Social Medicine 2: 63-66.

Singh, A.L., S. Fazal, F. Azam and A. Rahman. 1996. Income, environment and health. Habitat International 20(1): 77-91.

(Manuscript received on 30 November, 2015; revised on 10 May, 2016) 